\title{
DECISION ANALYTIC TOOLS FOR RESOLVING UNCERTAINTY IN THE ENERGY DEBATE
}

\author{
O. RENN \\ Nuclear Research Centre Jülich, Program Group Technology and Society, Post Box 1913, D-5170 Jülich. Fed. Rep. Germamy
}

Received August 1985

\begin{abstract}
Within the context of a Social Compatibility Study on Energy Supply Systems a complex decision making model was used to incorporate scientific expertize and public participation into the process of policy formulation and evaluation. The study was directed by the program group "Technology and Society" of the Nuclear Research Centre Jülich. It consisted of three parts: First, with the aid of value tree analysis the whole spectrum of concern and dimensions relevant to the energy issue in Germany was collected and structured in a combined value tree representing the values and criteria of nine important interest groups in the Federal Republic of Germany. Second, the revealed criteria were translated into indicators. Four different energy scenarios were evaluated with respect to each indicator making use of physical measurement, literature review and expert surveys. Third. the weights for each indicator were elicited by interviewing randomly chosen citizens. Those citizens were informed about the scenarios and their impacts prior to the weighting process in a four day seminar. As a result most citizens favoured more moderate energy scenarios assigning high priority to energy conservation. Nuclear energy was perceived as necessary energy source in the long run, but should be restricted to meet only the demand that cannot be covered by other energy means.
\end{abstract}

\section{Introduction}

In August 1982 the Ministry of Research and Technology of the Federal German Government asked the 'Technology and Society' Program Group of the Nuclear Research Centre, Jülich, to investigate the possibilities of designing an energy policy programme which would not only satisfy the needs and requirements of an energy-seeking society, but also provide a way of resolving the related conflicts within German society. The Jülich study group was asked to look into the conditions and prerequisites which are essential if we are to end up with a social consensus regarding an acceptable and viable path for future energy policies [1]. In particular the prospective outlook and the further development of nuclear energy were to be investigated, taking into account social and psychological aspects and constraints.

The project group at Jülich was formed in summer of 1982 from professionals drawn from the natural and social sciences. Research started in September of the same year. The final report was finished in mid-1984 and was published in spring 1985 .

Parallel to the Jülich study group the Ministry for Research and Technology asked a group of researchers from the universities of Essen and Frankfurt to study the social compatibility of current energy options using a different methodological approach. This project may be characterized as asking "what is socially acceptable?", i.e. how consistent are different energy options with certain present and projected goals, values and needs. The project takes a normative, largely qualitative approach. Energy options are evaluated on nine criteria in comprehensive analytical studies. The Jülich project is rather characterized as asking "what is socially accepted?", i.e. which criteria are empirically considered relevant for evaluating energy options and how are these options evaluated by randomly selected groups of citizens [2].

When designing the research program the study group had to consider the characteristics of the political arena in which energy policies have to be formulated and implemented.

In contrast to some other political arenas the energy scene in Germany, as in many other western countries, is characterized by the following four major features:

- A lack of unanimity among the scientific experts (or those regarded as experts) about facts.

- The public's lack of confidence in scientists and policy makers.

- The assignment of symbolic values to nuclear energy including moral and ethical considerations regarding 
industrial society as a whole.

-- The unwillingness of the stake-holder groups to move towards a compromise.

The lack of general agreement about future energy policies among experts, politicians and interest groups has led to frustrations amongst the general public and has promoted a feeling of distrust and scepticism towards official decision maker. Public media and opinion leaders have transferred the controversy to the public. forcing people into the role of arbitrators between scientific camps. Needless to say, most people found this too difficult and stressful. As long as every side claimed to be right, and in the eyes of the public nobody was able to prove which assessments were correct. a more cautious strategy was generally recommended. The result was a de facto moratorium on nuclear energy, though with the proviso that the nuclear option should be at least kept open [3].

Earlier studies by Battelle (Frankfurt) and the Systems Science Department at the Nuclear Research Centre in Karlsruhe demonstrated, that public perception of risk and benefit in the energy dabate focuses mainly on values associated with the use of nuclear energy [4]. Persons holding favourite attitudes towards economic growth and prosperity perceive nuclear energy in a positive manner, persons emphasising the necessity for environmental protection and nature conservation usually express negative views about the nuclear energy option. Thus, the energy question has been linked with symbolic contents and non-technical associations of individuals and groups. As a primary consequence value and interest groups took up the nuclear issue in order to increase their effort to please their own members and to recruit new ones. This has lead to a persistent tendency towards polarization between the pro- and anti-nuclear fractions in society. Since value conflicts cannot be resolved by factual arguments and most affected groups were convinced that they could not gain more power and influence by seeking a viable compromise, political paralysis has occurred. Just recently the readiness to negotiate for a compromise increased among the stake-holder groups as public attention shifted away from the nuclear issue. This was also a reason to start a new approach to design an energy policy on the basis of decison sciences incorporating conflicting values and interests.

\section{The basic steps of decision making}

According to the basic axioms [5] in decision theory any planning process consists of seven different steps:
Commitment and specification of needs or goals with respect to overall values in society.

Choice of appropriate criteria or dimensions which can be used as a heuristic classification to assess consequences for each option and to define violations or fullfillments of the specified goals or values.

Transformation of criteria in measurable indicators to assess the consequences of various options in a most objective manner.

Definition of options that are technically feasible and correspondive to the overall aim specified in the first and second step.

Assessment of consequences for each option according to the preformulated indicator list (extent and probabilities).

Assignment of relative weights to each indicator (or if appropriate -- subcriterion).

- Selection of an aggregate model to combine assessment probabilities and weights. Usually for each indicator the assessments are multiplied with the perceived probability and with the relative weight and afterwards summed up [6].

As long as the total range of consequential effects (from best to worse) is taken into account, as long as individual utility functions for variations in probabilities are considered and as long as independence and non-redundancy of all dimensions have been assured. the seven-step model has proved to be an excellent normative guideline for rational decision making [7]. But this good record can only be applied for decision making by individuals or by homogeneous groups. As soon as different groups with different criteria and values are an integral part in the decision-making process. the simple model fails, because rationally derived means to summarize values or to aggregate weights between groups are missing. All attempts to construct social utility functions are either too abstract so that they are impossible to use in a concrete case or they are rather apt to strategic manoeuvres [8]. Neither the Pareto optimality rule nor the Kaldor-Hicks-Criterion can provide a rational procedure of decision making if conflicts between groups have to be resolved. In particular the amount of necessary compensation which should be paid to those groups which feel deprivileged by the chosen option, cannot be determined on a rational basis. The difference of marginal utility of money among various income groups has to be considered [9], different conceptions of what people perceive as just, are difficult to incorporate into compensation strategies, feed back of information between compensated groups evokes anger and dissatisfaction (if one person notices that another person has gained more compensation than 
he himself), and the organisational structure of groups and their distribution of actual power make economic compensation [10] unfeasible in the political bargaining process.

Game theoretical models have been proposed lately to describe more precisely the behaviour of groups in conflict, but they cannot provide rational instruments for public policy makers of how to deal with conflictual situations and of how to make optimal decisions when facts and values are disputed in the public.

\section{A pluralist approach to decision making under conflict}

Any approach to build a model for decision making in energy planning has to face the difficulty that not only values and criteria are disputed, but also the facts, e.g. the assessments with respect to each option. Thus disagreement is expected to appear also in step 5 describing the assessment of consequences and the transformation to indicators. This specific situation leads to the necessity to alter the seven steps of decision making in order to cope with the conflictual situation and to gain approval by the different stake-holder groups which take part in the decision-making process. Since we basically followed the idea of the seven step model of decision making, we can best describe our approach by referring to this concept:

\subsection{The definitions and specifications of goals and needs}

We discussed this topic intensively asking if the government in a pluralist society is able to specify universal goals and needs or if all groups in society should have an equal right to come up with their own definitions what society should aim to. We decided that any political system - even the most democratic society - should base their decisions on a few meta-criteria, namely that the physical needs of the public should be served, that the civil rights should not be violated and that social change is not prevented or hindered. In the case of energy we specified these criteria in the following way: energy systems should provide all the services that people demand today and they will probably demand in the future; energy systems should not lead to a police state in order to insure the protection against sabotage or terrorism nor to control state laws on energy conservation; energy systems should be flexible enough to adjust to changes in the societal structure of needs and demands. These criteria were considered as meta-criteria for the energy planning process regardless if groups in the society shared this view or not. As expected there were no objections from any group with respect to these three meta-criteria. The meta-criteria were used later to specify the options that were regarded feasible. Any option which did not meet one of the metacriteria was excluded from the analysis.

\subsection{The selection of criteria}

The choice of appropriate criteria beyond the rather abstract level of metacriteria applied different procedures normally used in decision theory by asking the decision maker what matters to him. Firstly, we acknowledged that in democratic societies many decision makers are involved in energy planning, and secondly, that relevant groups in society demand that their values and interests should be considered when making collectively binding judgements. Thus, the problem had to be solved in which way we could select appropriate criteria that in principle could be approved by a group of heterogenious decision makers and be accepted by major interest groups in society. We could use intuition, analysis of current documents in the political debate, brainstorming with experts, the revealed preference approach [11] or surveys among the public. But these methods don't meet the two relevant conditions: approval by the decision makers and acceptance by societal groups. Thus we came up with a rather new technique referred to as value tree analysis, which was developed at the Social Science Research Centre of the University of Southern California.

The value tree analysis is an interactive, iterative and integrative method. Individuals or representatives or important societal groups are interviewed in order to determine their relevant values and concerns about the domain of investigation. The values identified as statements about desired states, positive intentions or preferred directions with respect to possible decision options are organized in a value tree representing the hierarchy of values of the particular group. Each group had to approve of its value tree.

In order to cover the wide spectrum of views on energy systems in the contemporary German society, ten stake-holder groups were invited for the value tree analysis. The politically most controversial organizations were probably the Power Plant Manufacturer and the Federation of Citizen Environmental Groups. Unfortunately, the latter decided not to participate. With the remaining groups and organizations nine individual value trees were constructed. Thus, we ended up with nine trees for the organizations given in table 1.

The value tree represents a hierarchical structure with the general values and concerns on top, and the 
Table 1

Classification of groups and organizations

Association of German Engineers

Ecological Research Institutes

Electric Power Company

Federation of the German Industries

Catholic Church

German Labour Union

German Society for Nature Protection

Power Plant Manufacturer

Protestant Church

specific criteria and value dimensions at the bottom. Most of the groups have a common understanding of the basic objectives for energy systems but differ in their main areas of concern. Accordingly, the individual trees have a similar superstructure with different focus on the degree of refinement of particular branches. Without giving preference to any individual value tree, the tree structures for the German Catholic Church (table 2) and for the Federation of the German Industries (table 3 ) are presented here.

The main objective of constructing individual value trees has been the formation of a combined value tree for all groups. Such a joint tree can be understood as the representation of major concerns in a pluralist society without focusing on the differences in weighting and importance for each value item. But the combined tree represents more than just a list of concerns menlioned during group interviews. It is an attempt to structure various, even conflicting values and criteria in a logically consistent, generally acceptable scheme which

Table 2

Value tree structure - Catholic Church

\section{"Relative risks"}

Life

- Accidents

- Health

Biological conditions of life

Nature

- Maintenance of species

- Maintenance of landscape

Ecological balance

Social and moral risks

-. Apathy

-. Uniformity

- Agression

Loss of fantasy

- Restrictions of development opportunities

Fears, fright

Risk to cultural values

\section{"Absolute risks"}

War potential

Catastrophes

Long term impacts threatening mankind (e.g. genetic)

Risk to the human identity

Freedom to act and change

Short and medium term

- Avoid totalitarism

- Maintain pluralism

-Create a differentiated spectrum of possible lifestyles

Long term

- Self-determination of future generations

- Avoid irreversible changes to the identity of humans Avoid anonymity

\section{Justice and social security}

For individuals

- Employment

- Possibility for responsible self-determination

- Quality of life

For countries

.. Avoid endangering cultural values and people's identity in developing countries

- Distributional justice

- International co-operation

- Availability of technologies for other countries

Furthering basic values

In the style of discourse among people

Factualness

Trutbfulness

Four cardinal values

- Modesty

- Justice

- Prudence

- Fortitude

Three evangelic recommendations

-- Poverty

- Obedience

Celibacy 
is meant to be the first step of a meta-semantic framework in forming a societal consensus on conflict resolution [12].

The combined value tree was generated in the following way. The main values of the overall tree were generated by clustering and contrasting the general values of the separate trees. All other items and terms were listed according to the hierarchical level of appearance. Then, the whole set was sorted and clustered around the respective lexical content of the main values. Finally, the clusters were aggregated and rearranged hierarchically in the overall tree with the eight main criteria: energy systems aspects, national economic impacts, impacts on the natural environment, health and safety, political impacts, social impacts, international impacts.

The criteria "energy systems aspects" and "national economic impacts" cover costs, efficiencies, securities, and market consequences of different energy systems. The criteria "impacts on the natural environment" and "health and safety" are self-explanatory. The criteria "political impacts" and "social impacts" include consequences for the social structure, quality of life, political decision processes, democracy and its institutions, options for future generations, etc. The criterion "international impacts" includes issues of peace, international distributional justice, and options of international policy.

The combined tree contains the concerns and evaluative criteria of all participating groups. All groups were asked to approve of the overall value tree. We pointed out to them though, that each item on the tree could be weighted by zero and thus vanished. For this reason an agreement among the interviewed groups could be reached, since every group found itself represented. Furthermore each group could abolish those criteria which the group representatives found unnecessary. It should be noted that in this step a compromise between groups was not needed, as all concerns were selected regardless if they were perceived as important or not. Therefore the joint tree is assumed to account for all viewpoints in the German society on energy system options. Since the main interest is concentrated on societal and individual issues here, the social and political criteria of the combined value tree are reproduced only (tables 4 and 5).

By using the joint value tree as criteria list we were able to meet the second condition - approval by societal groups - by definition. The political decision makers should also be satisfied with the catalogue of criteria, since the main interest is to maximize public support (as stated in our first assumption). A criteria list which combines all the concerns of the relevant groups is the best mean to assure public support. The only criticism
Table 3

Value tree structure - Federation of the German industries

Economic impacts

Costs

- Direct costs of energy production

- Indirect costs (e.g. through price increases of energy intensive products)

Social security

- Employment

- Wealth

Development opportunities for the market economy

Competitiveness

lnnovation

Development of export markets

Distributional justice

Degrees of freedom of the market economy

- Flexibility

- Openness

- Adaptability

\section{Energy systems security}

Security of energy supplies

- Availability of fuels

- Diversity of supply

Technical security

- Accidents during operations

- Other accidents

Political security

- Dependence (fuel, etc.)

- Susceptibility to potential blackmail

- Reduction and avoidance of conflicts

- Peace

Environmental compatibility

Nature

- Preservation of species

- Ecological balance

People

Culture

International co-operation

Chances for international development of technologies

Reduction of the economic differential (developed and developing countries)

\section{Acceptance}

Degree of public approval (majorities)

Consideration of minorities

- Protection of minorities

- Protection of majorities from disruption by minorities 
by politicians dealt with the large quantity of criteria that they were proposed to take into account. After receiving the list one decision maker groaned: "We are not work-aversive, but too much is too much".

Nevertheless the list was predominantly accepted as a useful tool to look into the consequences of different energy systems and to have an overview of the major concerns of societal groups with respect to energy systems.

\subsection{The transformation of criteria into indicators}

The next step refers to the transformation of the value tree structure into an operational system of di-

Table 4

Part of combined value tree structure - Social impacts

\section{Social impacts}

Quality of life

Cultural and moral quality of life

- Preservation of cultural goods

- Threats to cultural values

-. Loss of fantasy

- Agression

-. Apathy

- Uniformity

- Wastefulness

- Induced increase in consumption

- Threats to the human identity

- Anonymity

- Restriction of individual development options

- Fears

-- Disturbance of the relation between humans and nature

Social quality of life

- Social justice

- Social peace

- Social security

- Stable living

Economic quality of life

Employment

Wealth

- Energy services

- Heat

- Light

- Comfort

- Improvement of working conditions

Keeping societal options open, ability to change

Keeping options open for future generations

Enabling alternative lifestyles

- For individuals

For groups (e.g. religious, rural) mensions and indicators. Ideally this task should also be performed by the various groups forcing them to be more precise in what they mean by using various terms.

Table 5

Part of combined value tree structure - Political and international impacts

\section{Political impacts}

\section{Quality of political process}

Improvement of decision processes about energy systems

-- Trust

- Truthfulness

- Factualness

-- Preparedness to compromise

- Reason

Support by majorities

Consideration of minorities

Protection of minorities

- Protection of the majority from disruptions by minorities

Enhancement of justice and democracy

Conformity with laws

- Basic constitutional law Other laws

Local and regional distributional justice

Enhancement of pluralism

- Reduction of totalitarian tendencies

- Reduction of expert rules and elitist tendencies

Enhancement of autonomy

- Individuals

-. Institutions

Local/regional autonomy

\section{International impacts}

\section{Securing peace}

Reduction of the potential for conflicts

-- Threat potential

-... Terrorism potential

- Blackmail potential

Reduction of potential for crises

International distributional justice

Aid for developing countries (e.g. technology, economic) Keeping options of other countries open

- Preservation of cultural values

- Preservation of resources

Degrees of freedom in international politics

- National independence

- International co-operation (e.g. labour unions, scientific organizations) 
But because of the lack of time of the representatives of each group and the difficulty of combining different operational definitions of the same term, we used our own expertise and transformed all lower level criteria into indicators which in principle gave us a possibility for physical measurement or at least expert rating.

Our group catagorized the eight main criteria of the combined tree with up to five sub-levels of goals, concerns and values into a catalogue of nine criteria with up to ten sub-criteria each. Requiring simplification of clusters and aggregation of branches this process has to maintain the content and the meaning of the overall tree. It resulted in the following categories: operationality of the energy system, environmental impacts, health and safety, security of supply, economic effects, international effects, political impacts, social impacts, personal impacts, which are listed here with their pertaining sub-criteria (table 6).

Having settled the criteria and sub-criteria, in the next step our group had to find a strategy to oper-

Table 6

Catalogue of criteria and sub-criteria

Operability of the energy system

Technical efficiency of energy installations

Potential to meet energy demand

Demand for capital, manpower, energy

Emissions

\section{Environmental impacts}

Quality of air, soil, water

Change of climate

Effects on flora, fauna

Potential for catastrophic damage, pollution

Change of scenery

Change of settlements

Health and safety

Risks for the employees

Risks for the public

Potential threat of catastrophes

Problems for future generations

Security of supply

Geological availability

Political availability

Economic availability

Technical availability

Flexibility

Economic effects

\section{Profitability}

Expenditures

Capital investment

Standard of life

Labour market

Export competitiveness

Balance of payments

Impulse on innovation

Compatibility with the market economy

Homogeneity of regional development $\underline{\text { International effects }}$

Freedom of action

Security

Co-operation

Economic relations

Political impacts

Regulation of the energy consumption

Legal rights

Control and participation

Potential to meet public consent

Continuity of the democratic system

\section{Social impacts}

Equal opportunity

Social security

Quality of labour

Openness for various life-styles

Ecological sentiment

Personal impacts

Contentment with the conditions of life

Fears

Alineation

Self-determination 
ationalize the semantic concept onto the measurement level. Measurement rules or indicators were formulated for the relations which seemed to be well-suited to represent the intention of each corresponding term. Whenever possible, these indicators with their measurement instructions and scales have been derived at the lowest levels of the joint value tree. The remaining indicators were developed intuitively. All of them were checked by a number of experts for their degree of representativeness.

In response to the complexity of the technical information and the degree of uncertainty our group used different scaling levels: quantitative scaling, ordinal rating, rank order, controversial statements (nominal categories). In order to improve the readability and apprehension of the assessment all ratings were standardized on a four scale rating scheme (from very weak to very strong).

The final set of criteria and indicators is a possible approach to end up with a comprehensive, complete, independent, meaningful and adequate list for the examination of energy objects. The criteria have deliberately not been weighted, and the indicators have

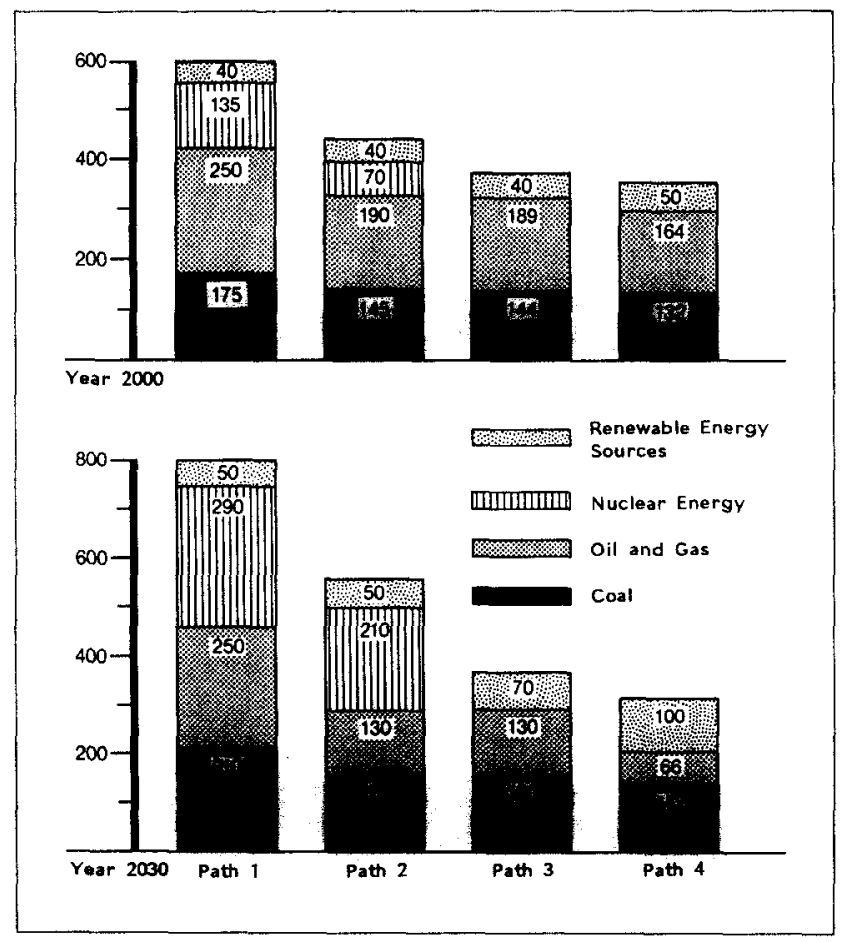

Fig. 1. Primary energy supply of the four energy scenarios for the years 2000 and 2030 . not been aggregated for the purpose of determining the pros and cons of each future energy option. Other studies on indicator systems may rely on different principles of classification and operationalization. Our choice seems to be justified for two reasons: the catalogue of criteria represents a common scheme of views on the energy situation which all German stake-holder groups were able to agree upon, and secondly, the particular system of criteria and indicators can be used as a general yardstick for the subjectively perceived consequences for each energy option.

\subsection{The generation of options}

On first glance it seems odd to look for possible options in such a late stage of the decision-making process. There are two reasons for the placement of this procedure after the specification of the evaluative criteria. Firstly, options generate positive or negative associations which unconsciously shape the analysts" selection of criteria and indicators. In most cases the criteria are defined in such way that the intuitively best option will be the "winner of the decision game". Secondly, the set of indicators and criteria are an excellent tool to search for new options which have not been in the discussion so far. Decision analysts have often pointed out the importance of the selection process regarding different options. If you know in advance. which criteria your options must meet, your imagination for totally new options might be encouraged and new solution might be envisaged [15].

In our study we did not construct our own scenarios. but used four existing ones.

In 1979, the German parliament unanimously passed the resolution to establish the Enquete-Commission on "Future Nuclear Energy Policy". The commission consisted of seven members of parliament and eight experts representing the fields of engineering, natural and social sciences. Because of the nuclear energy controversy in Germany and the development of the fast breeder reactor the commission assembled in so far proponents of the nuclear energy as well as opponents.

The commission designed four scenarios of future energy situations or paths into the energy future [14] which were supposed to comprise the full range of opinions on alternative energy systems. This range of prospective solutions did not only express the possible future mixes of the available energy sources but also the value orientations of the commission members.

The scenarios were constructed in such a way that different political options were operationalized in terms of consistent energy supply and demand models for the 
years 2000 and 2030 (the four scenarios are illustrated in fig. 1).

In particular the role of nuclear energy differs among the four scenarios: Path 1 and 2 utilize this technology to large extent, options 3 and 4 reject nuclear energy. With respect to energy conservation and solar systems paths 1 and 2 provide for a moderate amount of conservational and solar technologies, options 3 and 4 concentrate on these two aspects.

The advantage of using the four energy scenarios of the German Enquete-Commission is again the approval by most societal groups including pro and antinuclear activists. Both sides were represented within the four scenarios.

\subsection{Assessment of consequences according to the indicator list}

Since the facts dealing with the consequences of various energy systems are disputed among scientists, it was not possible to search in the literature for physical measurements of all indicators. At least we found quite a range of estimations which are partly dependent from the point of view that the analyst had taken in the energy debate. For many indicators, in particular those ones which referred to social and political aspects, the status of scientific methodology does not even allow a clear theoretical or empirical relationship between the implementation of any energy system and its possible outcomes. In this situation two methods of impact analysis were used:

- Professionals were asked to give estimations for each indicator that they felt to have expertise in. In addition they were asked to determine the range of other possible answers to the problem given a confidential interval of $95 \%$. Those ranges were collected and later sent back to each participant again, contrasting the position of each consultant with the ranges of all the other ones. After the revision we were in principle able to construct a probability function for each indicator summarizing the ranges given by each expert. To be honest we have to confess that this method did not work very well. Many of our experts used tremendously wide ranges in order to be on the safe side, whereas others changed their view dramatically over the period of questioning (two years). For many indicators the experts perceived no way of classifying a reasonable range and gave just their own opinion. Although we tried to reach as many experts as we could, the premise that each expert was allowed to respond only to those indicators that they felt competent on led to the result that some indicators were selected by al- most all experts, whereas others were not handled by any respondent. At the end we decided to use the responses by the different experts for a more or less "educated guess" which we thought was even better than reporting the results of the expert survey.

- We invited energy experts and trained professional in the field of impact analysis to a delphi seminar in order to assess the rather controversial economic, social, and political consequences of each energy option based on their best estimate of their factual knowledge.

A group of 17 experts employed at German universities or institutes was joined for a two day Delphi seminar. They were selected because they had previously published articles or books on social or economic impacts of energy systems. Deliberately we looked for scientists with different educational background. Engineers, natural scientists, economists and social scientists were invited to participate. We also tried to include persons with diverging attitudes towards the four scenarios. Because of time constraints the pronuclear side was slightly underrepresented.

The Delphi method is an iterative and integrative procedure used to arrive at a consensus on the forecast or estimate of specified future events or situations [13]. The experts are queried in iterative rounds with feedback supplied in between concerning the group's comments and responses.

We used a questionnaire containing the economic, social and political impacts with the associated indicators, because this part of the common catalogue of criteria seemed to be the most questionable with respect to the alternative future energy options. The evaluation process started with independent individual votes in the first round. In the second and third round sub-groups of about 4 participants had to consent to their group votes with minority and majority votes permitted. Each round was confronted with the frequencies of the particular indicator values achieved in the previous round. Finally, most of the discrepancies had been eliminated, revealing a set of estimates on the social and political consequences of the four energy paths.

Because the assessment has to be made for future energy situations, the participants made their intuitive subjective judgements based on a rather high degree of uncertainty. Ratings turned out to be generally sufficient for the indicators. The results are reproduced here in detail for the political impacts (table 7).

\subsection{Assignment of relative weights}

Similar to the selection of criteria and indicators it seems impossible to presume that there is an unanimous 
consent within society about the importance of each criterion with respect to the decision making process. With respect to the generation of values, no solution can be found except just eliciting weights among various groups of the general public and reporting them to the decision maker. There is no legitimate rationale to combine different assignments of weights into one societal weight. There are in principle four different approaches to come up with a generalized weight:

- Direct negotiations among the decision makers (unanimious vote).

- Selection of a few respresentatives out of the decision making body and using their mean weights (benevolent dictator).

- Utilization of different voting models (ordinal pair comparison, assignment of points, majority vote of options).

- Elicitation of weights among relevant groups in society and transfer of the results to client oriented politicians.
- Elicitation of weights among a representative sample of the general public and taking their mean value.

We tried to elicit the relative weights by organizing a survey of the general public (one man -- one vote), but we used the results of our surveys only as an informational input for the legitimate decision maker. We thought it necessary that the decision maker should have a most realistic picture as how the public at present assignes trade offs between different values. We rejected the idea of direct democracy for the following reasons:

- The public does not have to take responsibility for their judgements. Although the public has to live with its own decisions and should have an interest in a most rational approach to formulate judgements, there is no way of making them responsible, if the decision turnes out to be wrong. Neither the democratic sanction of election and re-election, nor legal sanctions as a result of political liability can be applied in public participation.

Table 7

Details of criteria and indicators with experts' Delphi estimates - Political impacts

$\begin{array}{llll}\text { Path } 1 & \text { Path } 2 & \text { Path } 3 & \end{array}$

$($ Path $=$ Scenario $)$

Regulation of the energy consumption

Political and moral appeals

Market intervention by financial measures

Administration of prices

State regulations and laws

\section{Legal rights}

Restriction of civil rights

State control

Control and participation

Transparency of the decision process

Participation of the citizens

Decision level

Potential to meet public consent

Unpopular measures

Potential for conflicts

Protest against majority decisions

Continuity of the democratic system

Continuity of political institutions

Change of political goals
Dependency on experts

$\begin{array}{ll}\gamma+ & 0 \\ +\gamma & 0 / \\ \gamma+ & 0 / \\ 0 & 0\end{array}$

$0 /+$
+
0
0

$+1++$

$++$

()

$0 /+1$

$\begin{array}{cccc}++ & + & 0 & 0 \\ ++ & + & -/ 0 & -/ 0\end{array}$

Explanation: - - Very low, - low, 0 indifferent, ++ very high, + high, $/ 0$ tendency, $+/++$ range. 
- The public is often not informed enough to correctly assess the consequences of different options. Since the assessment leads to considerable impacts on the evaluation, misperception of consequences results in a subjectively biased assignment of weights.

- The process of political decision making is iterative and cummulative, a survey among the public is punctual and singular. Even panel surveys cannot compensate for this short-coming.

- The construction of mean values of the public weights leads to strategic responses by the interviewed persons and to incorrect assignments of trade offs. In cases where the public only has the choice to select between predefined options, strategic responses are not possible. Strategy comes in if responses can be varied always to difficult degrees of approvement or disapprovement. In practise strategically operating groups have usually succeeded in linking simple choice question (like going nuclear or not) with other symbolic or political issues.

Some of the disadvantages of public surveys were overcome in our study by a special survey method, called planning cell procedure. Each planning cell consists of a group of citizens who are selected by a random process and are given paid leave from their workday obligations for a limited period of time in order to work out solutions for given, soluble planning problems with the assistence of advisors on procedure [16].

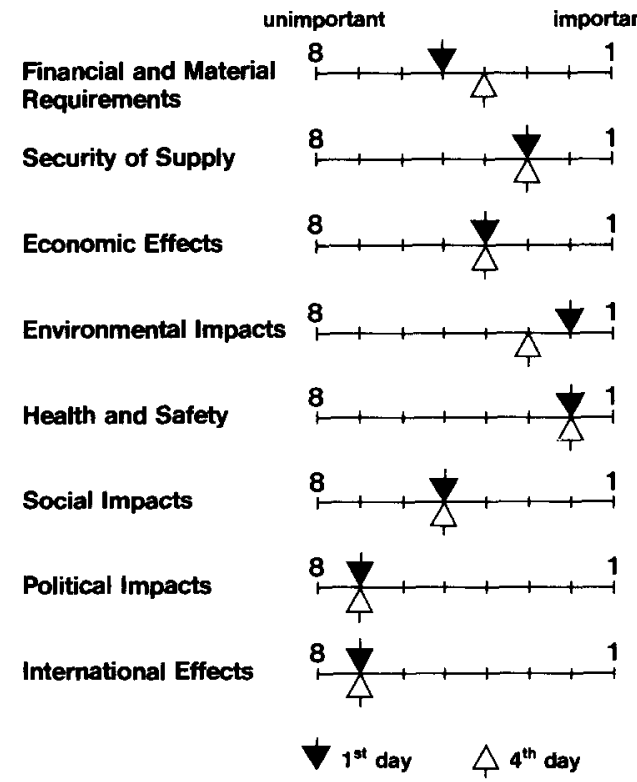

Fig. 2. Perceived degree of importance with respect to eight evaluative criteria measured at the first and last day of the planning cell experiment.
A group of citizens actually means a small group of about 25 people who work on the predefined task in a group process. Since the citizens involved have been selected by a random procedure they are not individually concerned in the planning problems to be solved. In order to encourage them to participate they are assigned the socially highly esteemed role of a "consultant" in the public planning process. The seriousness of the planning task to be solved is also made clear by the honorarium which the citizen receives for his function as a "consultant". The limited participation period prevents the citizen from being alienated from his real social role; he only changes his perspectives for a brief period.

In our compatibility study 24 planning cells all over Germany were organized and confronted with our impact analysis of the four energy scenarios. The task of the citizen was to rate each scenario according to the main criteria, put relative weights to each criterion and come up with a balanced recommendation which energy path should be taken by the German government. (Fig. 2 depicts the public ratings, fig. 3 the relative weights

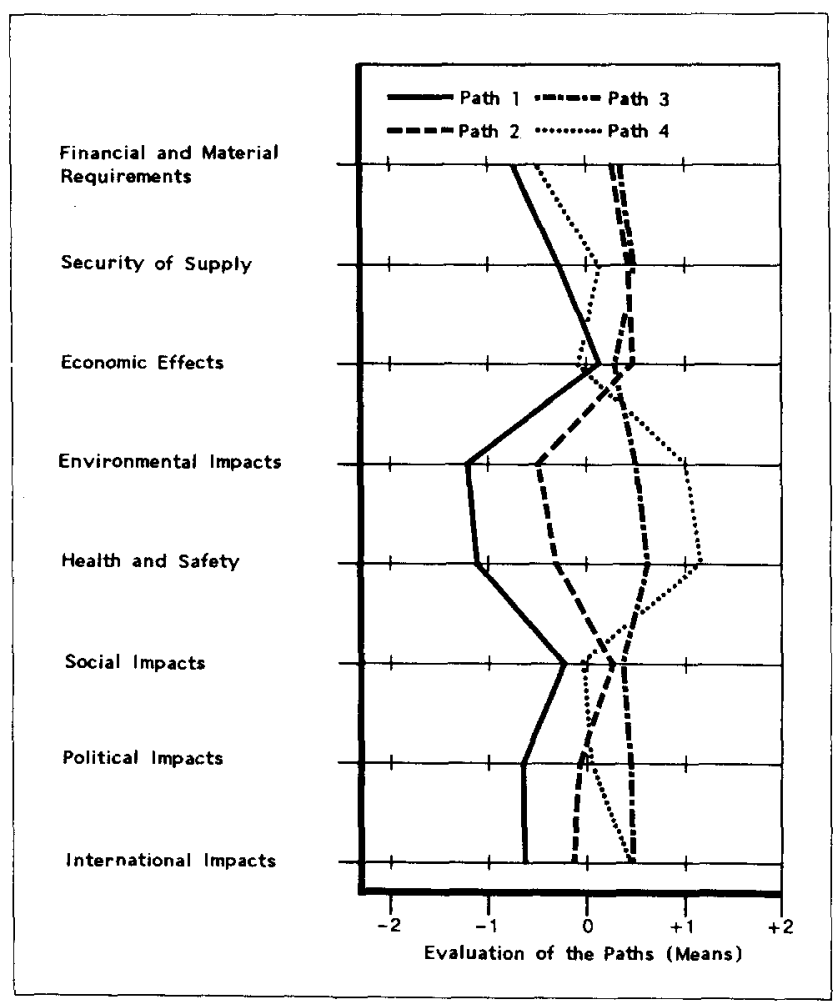

Fig. 3. Mean ratings of the four energy scenarios with respect to eight evaluative criteria. 
and fig. 4 the preference for the four energy paths.)

Again it should be emphasized that all the results of the planning cells are regarded as an input for the decisionmaking process. This input should be regarded as a decision aid to form and shape political judgements according to the latent and overt value structure of the concerned public. If this assumption is accepted, the planning cell might be a good instrument to collect the relevant feedback from society and to reveal the intuitive preferences and values that should be the guideline of democratic policy making.

\subsection{Aggregation of weighted assessments}

We considered the aggregation as a fundamental political process which should not be confined to mathematical formula. If the help of a decision analysist is still demanded (and this is usually not the case), he should concentrate on revealing the salient dimensions that define the borderlines between the preferences for one option or the others. May be specific political procedures can be implemented to overcome some negative impacts associated with the most promising option. May be a recombination of options can be initiated, may be a compromise can be found by compensation or by accepting compromises in other political issues. Negotiations are so complex that it is almost impossible to press them into a procedure of rational reasoning.

The dialogue of the decision maker with the policy maker is usually referred to as sensitivity analysis. By

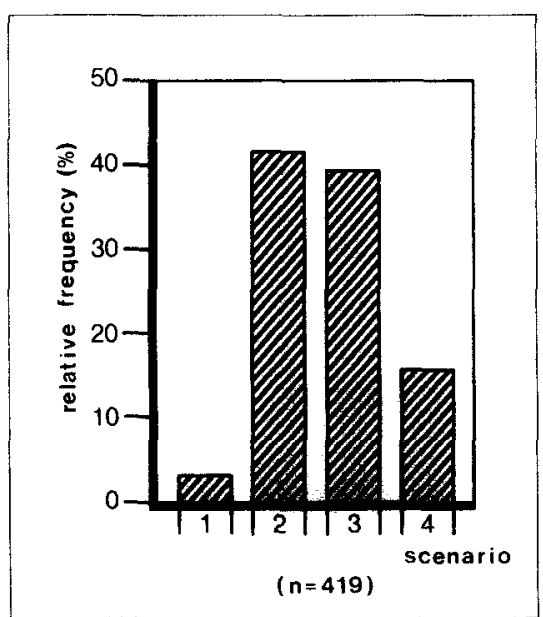

Fig. 4. Holistic preference of the planning cell members for one of the four energy scenarios. changing the different parameters or the different evaluations or assessments the decision maker gets a feeling which aspects exercise the strongest influence on the overall evaluation. Also he gets more aware of the uncertainties involved in any decision model. We think that it is most appropriate to combine the aggregation of the weighted assessments with the sensitivity analysis to provide a framework in which a most rational decision-making process can be initiated.

If the decision makers have a good impression of what to expect when aiming for any of the possible options, if they are sure that they have considered all relevant aspects and if they found a compromise in assigning weights to each dimension incorporating the wants and trade offs of the general public - if all this is accounted for, then the decision makers have all the necessary input to make a rational and for the time being non-improvable decision. There is no further need to confine the ultimate decision to a specific aggregational procedure.

\section{Conclusions}

The techniques and methods presented in this paper can be considered as an aid to improve the political decision-making process. In a society with pluralist vaiues and commitments technical and economic criteria are not sufficient for policy formulation and implementation. Potential conflicts have to be indentified in advance, and the pros and cons with respect to relevant societal groups have to be gathered and systematically classified.

The project of "social compatibility analysis" has been carried out to analyse, systematize and evaluate the interrelationship of energy systems characteristics and their societal perception. The comparison of the assessment profiles with holistic judgements of the possible future energy options can probably help to find desirable and acceptable solutions of technical development for the society.

For this purpose we have enlargened the traditional decision theoretical approach to incorporate conflict resolution and pluralist value commitments. There is no ideal solution to the problem of decision making in modern democratic societies when facts and values are under dispute. We are not sure if our model will work in any situation. It is also doubtful that this model can be transferred to other countries or other issues. We have the feeling, however, that it can be regarded as a first step in a more rational approach to policy making and planning in pluralist societies. 


\section{References}

[1] O. Renn, H.U. Stegelmann, G. Albrecht, U. Kotte and H.P. Peters, Citizens' preferences among energy scenarios, Technological Forecasting and Social Change 26 (1984) $12-46$.

O. Renn, G. Albrecht, U. Kotte, H.P. Peters and H.U. Stegelmann, Sozialverträgliche Energiepolitik, Ein Gutachten für die Bundesregierung (HighTech, München, 1985).

[2] H. Jungermann, The social compatibility of energy technologies - Theoretical and empirical approaches in West Germany, paper presented at the Advanced Study Institute (ASI) Technology Assessment, Environmental Impact Assessment and Riusk Analysis: Contributions from the Psychological and Decision Sciences, Les Arcs (France), August 21-31, 1983, to appear.

K.M. Meyer-Abich and B. Schefold, Wie möchten wir in Zukunft leben? Der "harte" und der "sanfte" Weg (C.H. Beck, München, 1981).

[3] H. Nowotny, Social aspects of the nuclear power controversy, Research Memorandum RM-76-33, IIASA, Laxenburg (1976).

[4] Battelle Institute. Einstellungen und Verhalten der Bevölkerung gegenüber verschiedenen Energiegewinnungsarten, report for the Ministry for Research and Technology, Frankfurt am Main (1977).

G. Frederichs, G. Bechmann and F. Gloede, Großtechnologien in der gesellschaftlichen Kontroverse, Ergebnisse einer Bevölkerungsumfrage zu Energiepolitik, Kernenergie und Kohle, KfK-Report 3342, Nuclear Research Centre Karlsruhe (1983).

[5] P.J. Gardiner and W. Edwards, Public values: Multiattribute-utility measurement for social decision making, in: Human Judgment and Decision Processes, ed. M.F. Kaplan and S. Schwartz (Academic Press, New York, 1975).

R.L. Keeney and H. Raiffa, Decisions with Multiple Objectives: Preferences and Value Trade Offs (Wiley, New York, 1976).

[6] R. Behn and J.W. Vaupel, Quick Analysis for Busy Decision Makers (Basic Books, New York, 1982) p. 19. (There are five steps reported, since the elicitation of goals and criteria are not included in the decision making process). E. Vedung, Politically accetable risks from energy technologies: Some concepts and hypotheses, in: Energy Risk Management, ed. G.T. Goodman, W.D. Rowe (Academic Press, London, New York, 1979) pp. 315-316.

[7] B. Fischoff, S. Lichtenstein, P. Slovic, R. Keeney and S.
Derby, Approaches to acceptable risk: A critical guide report, NUREG/CR-1614, ORNC/Sub-7566/1, Oak Ridge, Eugene, San Francisco, Stanford (1980) pp. 174-200.

[8] J.W. Lathrop, S.R. Watson, Decision analysis for the evaluation of risk in nuclear waste management, in: Risk: A Seminar Series, ed. H. Kunreuther, IIASA Collaborative Proceedings Series, CP-82-52 (International Institute for Applied Systems Analysis, Laxenburg, 1981) pp. 404-405.

[9] M.M. Hufschmidt, New approaches to economic analysis of natural resources and environmental Quality, in: Economic Approaches to Natural Resource and Environmental Quality Analysis, ed. M.M. Hufschmidt and E.C. Hyman (Tycooly International Publishing, Dublin. 1979) pp. 6-7.

[10] O. Renn, Methodological approaches to the assessment of social and societal risks, in: Beyond the Energy Crisis Opportunity and Challenge, Vol IV, eds. R.A. Fazzolare and C.B. Smith (Pergamon Press, Oxford, New York, 1981) pp. A376-379.

[11] E.U. Kotte, Extended risk and benefit evaluation of energy systems for policy analysis, Lecture at the International Symposium on the Risks and Benefits of Energy Systems, organized by the International Atomic Energy Agency (IAEA), United Nations Environment Programme (UNEP) and the World Health Organization (WHO), Jülich, April 9-13, 1984, submitted manuscript, to appear.

[12] R. Keeney, O. Renn, D. von Winterfeldt and U. Kotte, Die Wertbaumanalyse, Entscheidungshilfe für die Politik (HighTech, München, 1984).

[13] D. von Winterfeldt and G.W. Fischer: Multiattribute utility theory: Models and assessment procedures, in: Utility, Probability and Human Decision Making, eds. D. Wendt and C. Vlek (Reidel, Dordrecht, Holland, 1975) pp. 47-86.

[14] Zur Sache 1/80, Zukünftige Kernenergie-Politik, report of the Enquete-Kommission des Deutschen Bundestages (Deutscher Bundestag Presse und Informationszentrum, Bonn, 1980).

[15] J.F. Preble, Public sector use of the Delphi technique, Technological Forecasting and Social Change, 23, (ISB) p. $75-88$.

[16] P.C. Dienel, New Options for participatory democracy, Werkstatt-Papier No. 1 of the Research Team "Bürgerbeteiligung \& Planungsverfahren" (University of Wuppertal, Wuppertal, 1980).

P.C. Dienel, Die Planungszelle (Westdeutscher Verlag, Opladen, 1978). 